\title{
Endocrine control of antler growth in red deer stags
}

\author{
J. M. Suttie†, G. A. Lincoln* and R. N. B. Kay \\ Physiology Department, Rowett Research Institute, Bucksburn, Aberdeen AB9 2SB and *M.R.C. \\ Unit of Reproductive Biology, 37 Chalmers Street, Edinburgh EH3 9EW, U.K.
}

\begin{abstract}
Summary. Observations of body weight, testis size, antler status, plasma testosterone and prolactin were made on 12 red deer stags during their first 2 years of life. Six of the stags were fed to appetite throughout the study (Group A) and 6 were fed a $70 \%$ restricted diet during each winter (Group B). In addition 6 of the stags, 3 from each group, were studied in more detail; $\mathrm{LH}$ and testosterone were measured either after a single injection of LH-RH or in samples taken at frequent intervals over a period of 8 or $24 \mathrm{~h}$. During the study the stags became sexually mature, developed first their pedicles and then antlers and showed at least one complete cycle of casting and regrowth of the antlers. The stags in Group A developed their testes and pedicles about 2 months earlier than did those in Group B. Pedicle initiation was associated with increasing plasma testosterone levels in response to changes in LH secretion, and antler development occurred when testosterone levels were low or decreasing. Cleaning of the velvet was associated with high levels of plasma testosterone. Antler casting occurred when plasma testosterone concentrations were low or undetectable and prolactin levels were high or increasing. The relationship between $\mathrm{LH}$ and testosterone varied during the study; in spring when the testes and antlers were growing, relatively high levels of LH were associated with only small peaks of testosterone, yet in summer, when antler growth was complete and the antlers were clean of velvet, low $\mathrm{LH}$ concentrations were associated with large peaks of testosterone.
\end{abstract}

\section{Introduction}

Antlers, organs of bone, are male secondary sexual characteristics in red deer and function in intrasexual and intraspecific competition (Darling, 1937; Chapman, 1975). The deciduous antlers grow from permanent pedicles which are first developed at puberty under the influence of testosterone secreted by the testes (Lincoln, 1971a). The seasonal cycle of casting and regrowth of the antlers is also dictated by changes in testosterone : casting and regrowth occurring in the spring and summer when the testosterone levels are very low during the non-mating season, and maturation of the hard antler occurring in the autumn when the testosterone levels increase before the mating season (Wislocki, Aub \& Waldo, 1947; Lincoln, Youngson \& Short, 1970; Lincoln, 1971b; Lincoln, Guinness \& Short, 1972; Bubenik, Bubenik, Brown \& Wilson, 1975; Lincoln \& Kay, 1979). There is, however, some evidence that casting and regrowth of the antlers is stimulated in the spring by endocrine changes other than the seasonal decline in testosterone (Wislocki et al., 1947; Tachezy, 1956; West \& Nordan, 1976; Mirarchi, Howland, Scanlon, Kirkpatrick \& Sanford, 1978).

In the present study plasma testosterone and prolactin concentrations were analysed over 2 years and attempts were made to correlate the changes in secretion of LH and testosterone with those of the antlers.

$\uparrow$ Present address: Invermay Agricultural Research Centre, Private Bag, Mosgiel, New Zealand. 


\section{Materials and Methods}

The animals were divided into two groups receiving different feeding regimens as part of another study (Suttie, Goodall, Pennie \& Kay, 1983). Six of the stags were fed a concentrate diet to appetite throughout the period (Group A) and the remainder (Group B) were fed $70 \%$ as much from August 1977 until May 1978, and from November 1978 until May 1979, and to appetite during the summer of 1979. The stags were penned separately in a room with natural photoperiod, although they could see, smell, hear and touch each other.

At 1-or 3-weekly intervals, from June 1977 when the stags were 2 weeks old until July 1979 when they were 106 weeks old, each of the 12 animals was weighed, antler length measured, antler status recorded, testis diameter measured to the nearest $0.1 \mathrm{~cm}$ with vernier callipers and a jugular blood sample withdrawn into a pre-heparinized evacuated tube.

On 14 occasions blood samples were withdrawn at 20-min intervals for $8 \mathrm{~h}$ from 6 of the stags ( 3 from Group A and 3 from Group B). For this each stag was restrained manually within his pen while a cannula (Braunula luer, Armour Pharmaceuticals) connected to polythene tubing was inserted into the jugular vein, sutured to the skin and secured to the hair of the neck and back. The tubing ended with a tap which was positioned above the rump, thus allowing blood samples to be taken with little difficulty or disturbance. A solution of heparinized saline was used to maintain the patency of the cannula. On two additional occasions, in May and September 1978, blood samples were collected at 30-min intervals for $24 \mathrm{~h}$ using the same technique.

In addition, the stags (three from each of Groups $A$ and $B$ ) were given an injection to the jugular vein of synthetic luteinizing hormone-releasing hormone (LH-RH: I.C.I. Pharmaceuticals) at a dose of $20 \mathrm{ng} / \mathrm{kg}$ in $2 \mathrm{ml} \mathrm{0.9 \%}$ (w/v) NaCl. Blood samples were collected at $0,10,40,75,120$ and 180 min relative to the time of the injection. All blood samples obtained during the study were heparinized, centrifuged within $20 \mathrm{~min}$ of collection, and the plasma stored at $-20^{\circ} \mathrm{C}$ until required for the assays.

Radioimmunoassays. The concentrations of $\mathrm{LH}$, prolactin and testosterone in the blood plasma samples were measured by radioimmunoassays. The method of Scaramuzzi, Caldwell \& Moor (1970) was used to measure the levels of LH; the assay had been validated for use with deer plasma in a previous study (Lincoln \& Kay, 1979). The assay had a sensitivity of $0.25 \mathrm{ng} / \mathrm{ml}$ plasma using NIH-LH-S11 as the reference standard. The method of Chesworth (1977) was used to measure the levels of prolactin. The assay was shown to have minimal cross-reactivity with ovine $\mathrm{LH}, \mathrm{GH}$ and TSH, and dilution of plasma from deer produced values parallel to the standard curve. The assay sensitivity was $0.25 \mathrm{ng} / \mathrm{ml}$ using NIH-P-S9 as the reference standard. The measurement of testosterone was by the method of Corker \& Davidson (1978) using an antiserum with a small crossreactivity with dihydrotestosterone $(20 \%)$ but otherwise specific. The lower limit of detection in this assay was $0.2 \mathrm{ng} / \mathrm{ml}$ plasma. For all assays the inter- and intra-assay coefficient of variation was $<13.6 \%$.

\section{Results}

\section{Puberty and the seasonal cycle}

The monthly changes in the length of the antlers, diameter of the testes, concentration of testosterone and prolactin, and the live body weight of the stags during the first 2 years of life are shown in Text-fig. 1. In Group A, the pedicles first began to develop in September or October at 4-5 months of age. At this time the animals were growing rapidly, the testes were increasing in size and the concentration of testosterone in the blood plasma had just increased to a level detectable by the radioimmunoassay $(>0.2 \mathrm{ng} / \mathrm{ml})$. Prolactin concentrations had fallen from the higher values during the first few months of life (Text-fig. 1a). 


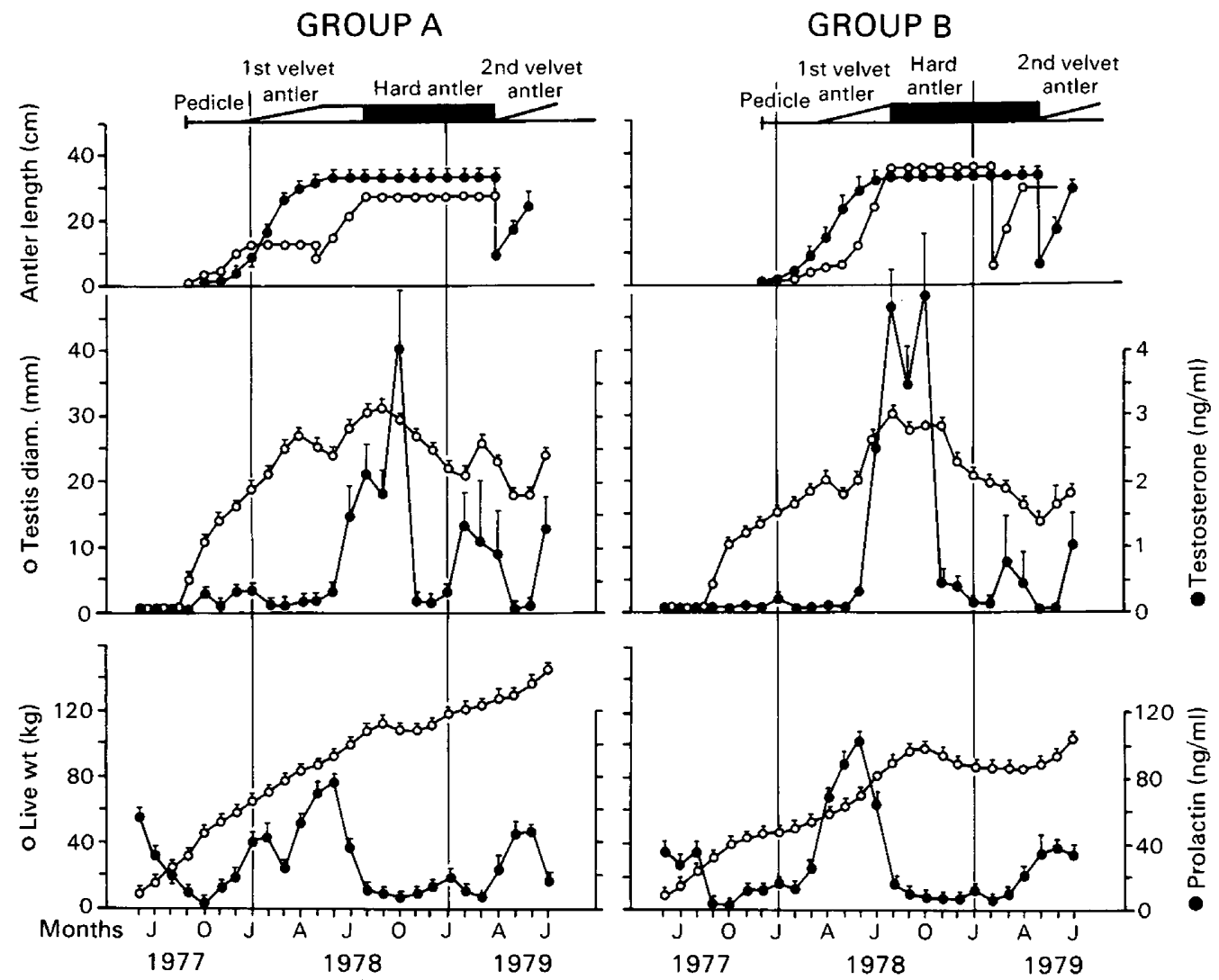

Text-fig. 1. Changes in antler length, testosterone and prolactin concentrations, testis diameter, and liveweight in red deer stags in Groups A and B from birth until 2 years of age. Values are mean \pm s.e.m. for 6 stags per group. The antler status is illustrated diagrammatically. In the antler length panels, $O$ is used to illustrate the antler cycle of the precocious stag in Group A (who grew 2 sets of antlers during his 1st year of life) and in Group B the stag who cast his antlers in February, substantially earlier than others of this group. Animals with precocious antler development or early casting are not included in the mean plot of antler length.

The pedicles were fully grown after 2-3 months and from these the velvet antlers developed during the first winter and spring; these first antlers were small and unbranched. At this time, the testes were still increasing in size, but the blood levels of testosterone were lower than at the stage of pedicle growth and the levels of prolactin were much higher. Five of the stags in Group A completed growth of the first antlers in the spring at about 9 months of age, but retained the antlers with the velvet skin still intact during the summer. The velvet was finally cleaned in early autumn at about 15 months of age, exposing the dead antler. During the summer the plasma concentration of testosterone was initially low, but increased markedly in the autumn; the level of prolactin was high in the summer and decreased in the autumn (Text-fig. 1a). When the antlers were cast testosterone concentrations were generally low although the blood levels of prolactin were increasing at this stage (Text-fig. la). The changes in the antlers and the other reproductive characteristics in Group B stags were broadly similar to those of Group A except that they were slightly delayed (Text-fig. 1b).

One of the stags in Group A was slightly precocious in its reproductive development compared to the others. The animal produced a small set of antlers in the first spring of life at 9 months of age 
and these became cleaned of velvet. The antlers were subsequently cast in the early summer after the initiation of new antler growth at the base of the antler and a second set of antlers, which had several branches although the shape was abnormal, developed during the summer. This stag cleaned the velvet from its antlers in the autumn as did the other stags in the group.

\section{Episodic secretion of $\mathrm{LH}$ and testosterone}

As shown in Text-fig. 2(a), the 8-h plasma profiles for the precocious Group-A animal revealed an increase in the concentrations of $\mathrm{LH}$ and testosterone during December-March when the animal was 6-9 months old and the first antlers had begun to develop. There were transitory peaks in the levels of $\mathrm{LH}$ and testosterone indicative of episodic secretion. The highest levels of LH occurred in December when the pedicles were fully grown while the highest levels of testosterone occurred in February shortly before the velvet was cleaned from the first set of antlers.

(a)

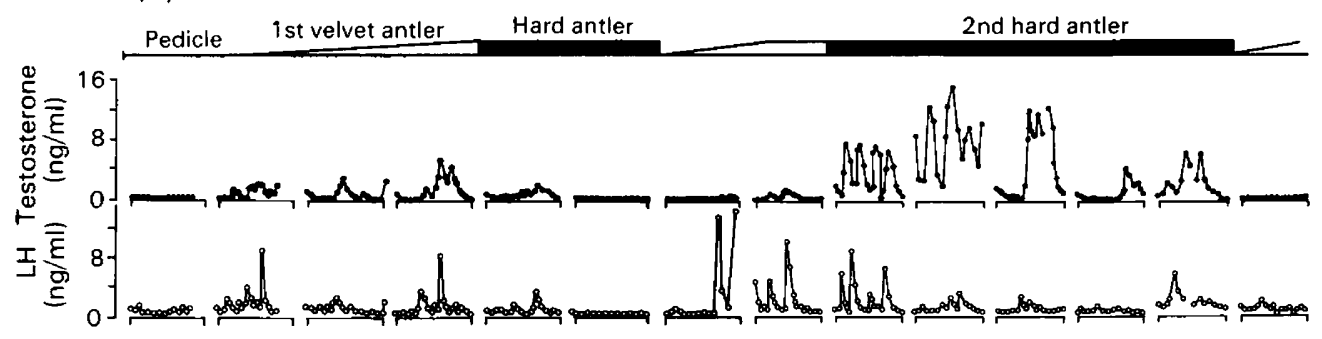

(b)

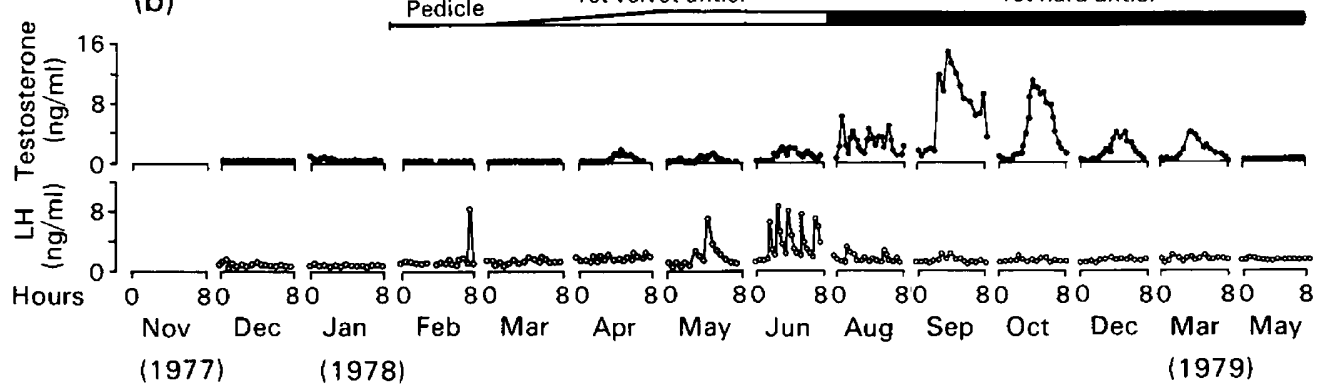

Text-fig. 2. The 8-h profiles of LH and testosterone concentrations, from November 1977 when the stags were 5 months old until May 1979 when the stags were 23 months old, for (a) the precocious stag in Group A and (b) a typical stag from Group B. Antler status is shown diagrammatically.

By April, when the stag was 10 months old the plasma levels of LH and testosterone had declined and there were no episodic peaks in the 8-h profile. At this time new antler growth was beginning from the pedicles, leading to the casting of the old antlers. From May to September there was a second increase in the plasma $\mathrm{LH}$ and testosterone values with the reappearance of an episodic pattern of secretion. At this time the hormonal profiles showed clearly the temporal correlation between the episodic peaks in the plasma levels of LH and those of testosterone. The plasma levels of LH and testosterone decreased from October and were again very low by the time the antlers were cast in the next spring. The 8-h profiles for the typical stage from Group B which also typified 5 of the 6 Group-A stags (Text-fig. 2b) were similar to those in the precocious Group-A animal except that the levels of both hormones remained low over the first 9 months of life. This correlated with the later development of the antlers. The increase in the levels of LH and testosterone during the first spring and summer was very similar in the 2 animals, with the initial 
appearance of episodic peaks in the levels of LH early in the season during antler growth, and the progressive increase in the secretion of testosterone associated with cleaning of the velvet from the antlers.

When 24-h samples were taken at two stages of the antler cycle (Text-fig. 3) there were several episodic peaks in the levels of LH in May, when the animals were in velvet, but the levels of testosterone remained low. In September, when the animals were in hard antler, the episodic peaks of $\mathrm{LH}$ were of lower amplitude but the levels of testosterone were greatly increased.

(a)

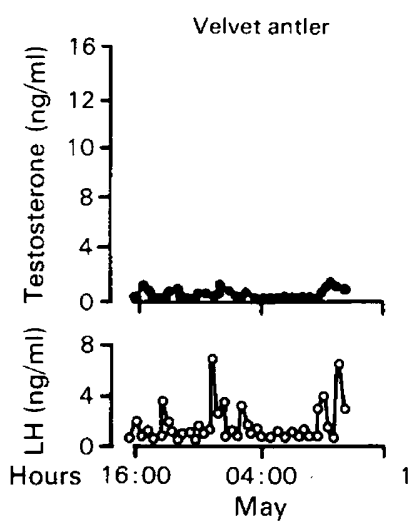

(b)
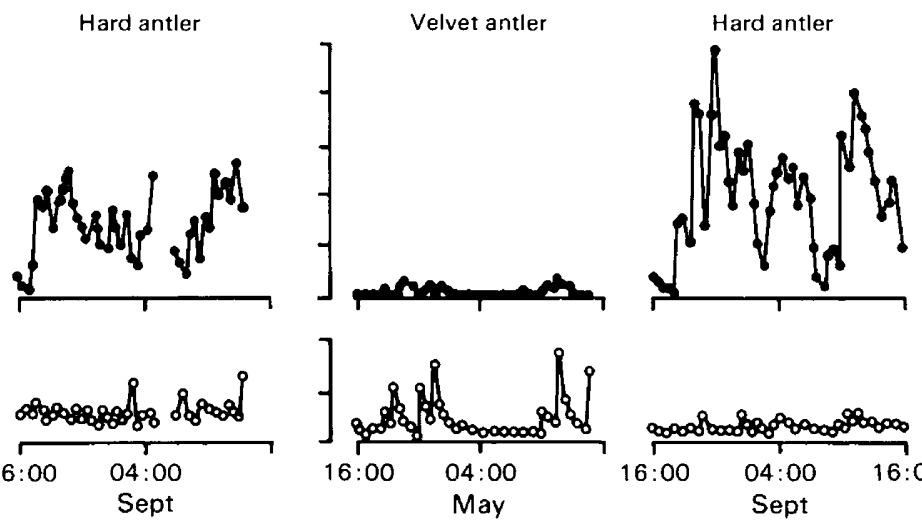
16:00 04:00 16:00

Text-fig. 3. The 24-h profiles of $\mathrm{LH}$ and testosterone concentrations for typical stags from (a) Group A and (b) Group B.

(a)

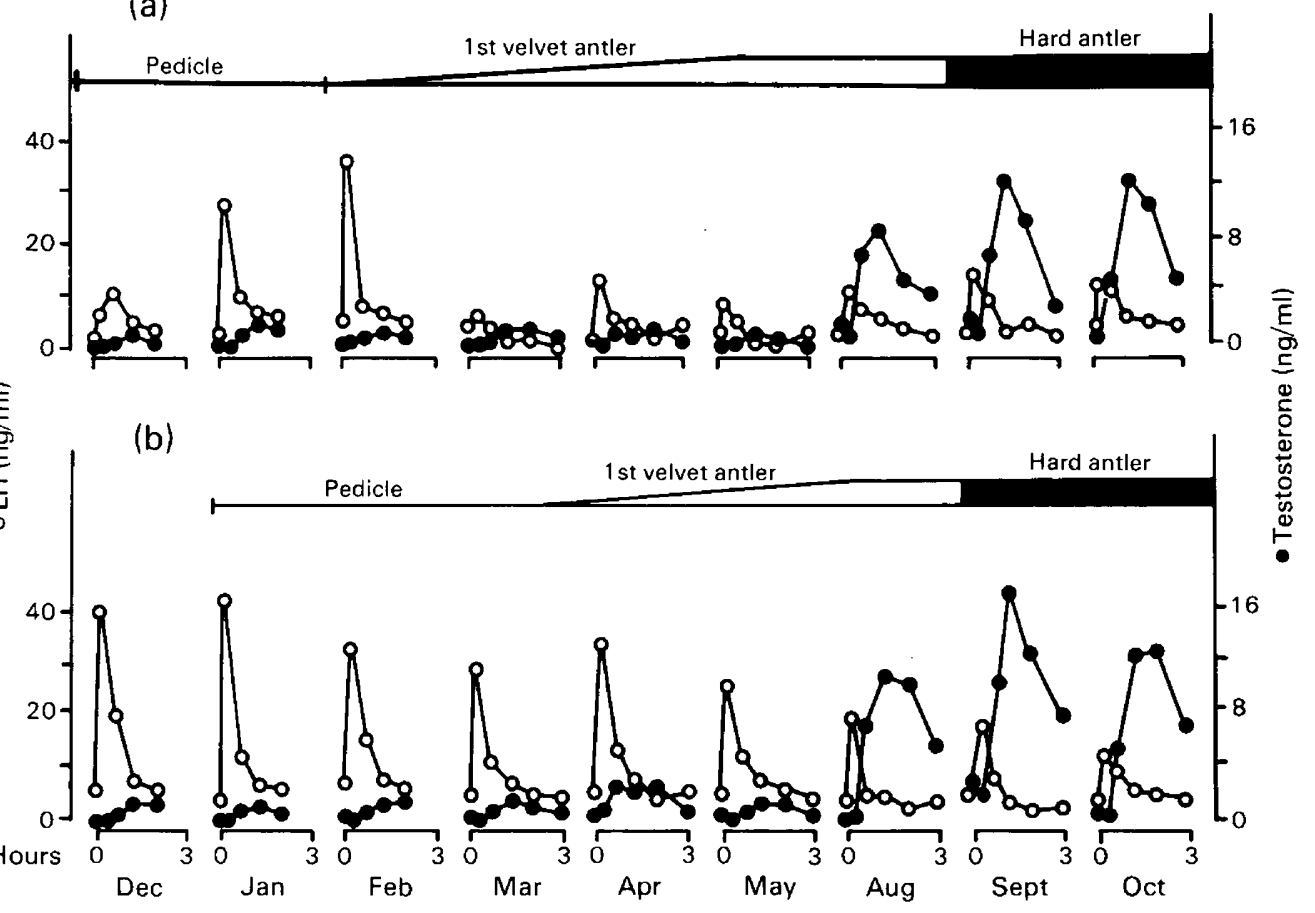

(1977)

Text-fig. 4. The response of $\mathrm{LH}$ and testosterone to a single injection of $\mathrm{LH}-\mathrm{RH}(20 \mathrm{ng} / \mathrm{kg})$ for typical stags in (a) Group A and (b) Group B. 


\section{Responses to $\mathrm{LH}-\mathrm{RH}$}

On all occasions when the animals were tested with LH-RH (Text-fig. 4) there was an immediate increase in the $\mathrm{LH}$ concentrations and a later increase in the testosterone values. There was a large increase in the $\mathrm{LH}$ response to $\mathrm{LH}-\mathrm{RH}$ when the stags were still immature and before the pedicles had begun to develop. At this time the testosterone response was very small. As the stags became older and developed the first hard antlers, the increase in LH in response to LH-RH became smaller, while the testosterone response became much larger. In September and October, when the stags were 16 months old, testosterone response was at a maximum. There was little difference due to diet in peak LH or testosterone response to LH-RH during the study, but LH levels were lower in the Group A stags in April and May (Table 1).

Table 1. Peak concentrations (mean \pm s.e.m.) of $\mathrm{LH}$ and testosterone in stags in Group A (unrestricted diet) and Group B (restricted diet) after an injection of $20 \mathrm{ng} \mathrm{LH}-\mathrm{RH} / \mathrm{kg}$ body weight

\begin{tabular}{|c|c|c|c|c|}
\hline & \multicolumn{2}{|c|}{$\mathrm{LH}(\mathrm{ng} / \mathrm{ml})$} & \multicolumn{2}{|c|}{ Testosterone $(\mathrm{ng} / \mathrm{ml})$} \\
\hline & Group A & Group B & Group A & Group B \\
\hline December & $18 \cdot 9 \pm 3 \cdot 7$ & $32 \cdot 8 \pm 7 \cdot 1$ & $2.2+0.5$ & $0.9+0.2$ \\
\hline January & $28.4 \pm 5.6$ & $39.6 \pm 3.5$ & $2.1 \pm 0.5$ & $1.2 \pm 0.2$ \\
\hline February & $21.4 \pm 6.4$ & $36.7 \pm 1.2$ & $1 \cdot 2 \pm 0.1$ & $1 \cdot 1 \pm 0.1$ \\
\hline March & $9.4 \pm 1.8$ & $19.5 \pm 4.0$ & $1.9 \pm 0.6$ & $2.2 \pm 0.3$ \\
\hline April & $17.6 \pm 7 \cdot 1$ & $31 \cdot 1 \pm 4 \cdot 2^{*}$ & $1.1 \pm 0.1$ & $1.8 \pm 0.5$ \\
\hline May & $6.6 \pm 0.3$ & $21.9 \pm 2.3^{*}$ & $0.6 \pm 0.1$ & $0.7 \pm 0.2$ \\
\hline August & $9.1 \pm 0.3$ & $22 \cdot 2 \pm 1.4$ & $7.1 \pm 0.9$ & $9.9 \pm 0.8$ \\
\hline September & $15.0 \pm 4.2$ & $13.6 \pm 1.9$ & $11.5 \pm 0.8$ & $10 \cdot 6 \pm 1 \cdot 1$ \\
\hline October & $12.4 \pm 2.9$ & $13.3 \pm 2.3$ & $12.8 \pm 1.4$ & $13.6 \pm 3.1$ \\
\hline
\end{tabular}

${ }^{*} P<0.05$ compared with Group A values (Mann-Whitney U test).

The combined results for the 6 stags tested with LH-RH and those bled for $8 \mathrm{~h}$ monthly are shown in Text-fig. 5. Before the appearance of the pedicles and during the growth of the first antlers, mean daily levels of $\mathrm{LH}$ were low but there was a good LH response to LH-RH. At the same time the mean daily levels of testosterone were very low and there was a poor testosterone response to LH-RH. Nonetheless, both mean daily testosterone and testosterone response fell during the mid- and late velvet stages of antler development compared with late pedicle development. Later, when the first antlers had developed, the mean daily levels of $\mathrm{LH}$ were variable and the $\mathrm{LH}$ response to $\mathrm{LH}-\mathrm{RH}$ had decreased, while the mean daily levels of testosterone and the testosterone response to $\mathrm{LH}-\mathrm{RH}$ were increased.

\section{Discussion}

Pedicle development began at 4-5 months of age and 6-7 months of age for stags in Groups A and B respectively. For both groups this was at an earlier age than for deer living in the wild, especially those in areas of poor quality feeding such as the Highlands of Scotland (Mitchell, McCowan \& Nicholson, 1976; Mitchell, Staines \& Welch, 1977).

The development of pedicles correlated with the growth of the testes and the appearance of measurable amounts of testosterone in the peripheral blood. This is consistent with the effectiveness of testosterone in stimulating the development of pedicles in prepubertally castrated male deer (Wislocki et al., 1947). Growth of the first antler occurred when the plasma testosterone 


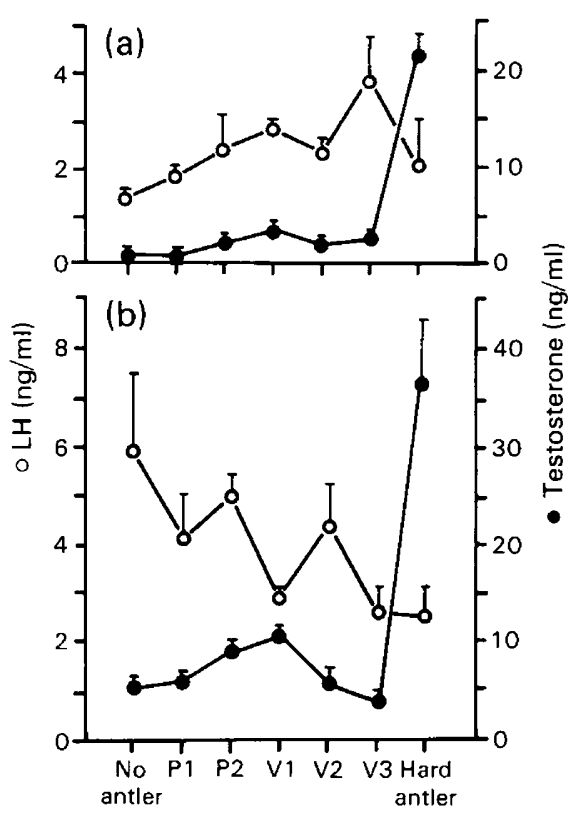

Text-fig. 5. The mean \pm s.e.m. concentrations of $\mathrm{LH}$ and testosterone (a) and the peak concentration of $\mathrm{LH}$ and testosterone after an injection of $20 \mathrm{ng} \mathrm{LH}-\mathrm{RH} / \mathrm{kg}$ body wt (b) at different stages of the antler cycle. In (a) each point represents the mean of 6 stags, and each mean is derived from an 8-h sampling period. In (b) each point represents the mean of 6 stags. $\mathrm{Pl}=$ early pedicles $(3 \mathrm{~cm}$ in length), $\mathrm{P} 2=$ late pedicles, $(3-6 \mathrm{~cm}$ in length) and V1, V2 and V3 represent early, mid- and late-antler growth respectively. The stag with precocious antler development was not included in the data presented in (a).

levels were low, although calcification and velvet cleaning took place when testosterone levels were high, i.e. in late summer, for all but one of the stags when they were aged 15 months. Treatment with testosterone during velvet antler growth is known to induce premature calcification of the antler in intact adult stags and velvet cleaning in adult castrated stags (Wislocki et al., 1947; Lincoln et al., 1970, 1972). Antler casting occurred after a period of very low levels of testosterone in spring. Castration when antlers are clean of velvet causes premature antler casting and administration of testosterone to intact stags delays casting (Wislocki et al., 1947; Goss, 1968; Lincoln et al., 1970, 1972). Medroxyprogesterone acetate administered to stags in hard antler also caused premature casting, presumably by reducing LH levels and thus testosterone levels (Muir, Barrell \& Sykes, 1982). Casting of the previous antler coincided with the annual increase in the plasma level of prolactin. Such entrainment to the photoperiod could be produced if prolactin is acting as an antigonadotrophin. Schulte et al. (1981) studied the influence of pinealectomy on prolactin secretion in white-tailed deer (Odocoileus virginianus) and found that pinealectomy altered the naturally occurring seasonal profile of serum prolactin. Since pinealectomy also delays antler casting by 2-3 months (Plotka, Seal, Letellier, Verme \& Ozoga, 1978), it is considered likely that the delay is due to the alteration in prolactin secretion. The summer peak of prolactin was lower in 1979 than 1978; as all samples from each animal were run in the same assay it is not possible that interassay variations account for this.

In view of the effects of testosterone it may be unnecessary to propose that other hormones influence the growth and development of antlers. However, there is no experimental proof that there is a cause-effect relationship between the low level of plasma testosterone and the actual growth of the antler in velvet. 
Plasma levels of LH increased in the young stags when the testes first began to enlarge and plasma levels of testosterone began to increase. There was also a change in plasma level of LH after puberty associated with the seasonal change in the plasma level of testosterone. This is consistent with the view that the secretion of LH by the anterior pituitary gland dictates the changes in the activity of the testes both at puberty and during the seasonal reproductive cycle (Pelletier \& Ortavant, 1975; Lee et al., 1976; Lincoln \& Davidson, 1977; Lincoln \& Kay, 1979). In the present study, short-term fluctuations in LH and testosterone concentrations were evident, indicative of episodic secretion, and this was most noticeable during the periods of increased secretory activity, e.g. June-September in the yearling stags. There was a temporal relationship between the variations in the two hormones with peaks in the levels of testosterone following peaks in the levels of LH, indicating a causal relationship (Katongole, Naftolin \& Short, 1971; Lincoln \& Kay, 1979).

LH-RH stimulated the release of $\mathrm{LH}$ and testosterone at all stages even when the endogenous release of $\mathrm{LH}$ was low. The $\mathrm{LH}$ response to $\mathrm{LH}-\mathrm{RH}$ was actually greatest when the endogenous secretion of LH was lowest, indicating that the reason for the lack of endogenous secretion was a lack of LH-RH secretion from the hypothalamus. When endogenous secretion of LH was increased there was a small $\mathrm{LH}$ response to the injection of LH-RH. However, this induced release of $\mathrm{LH}$ resulted in a large release of testosterone, confirming that there was an increase in the responsiveness of the testes at the peak of gonadal activity (Lincoln, 1976).

The overall results illustrate the way puberty and season influence the episodic secretion of LH and this dictates the changes in the activity of the testes and secretion of testosterone. The development of the antlers in the young stags, and the cycle of casting and regrowth of the antlers in the adult stags, are largely controlled by the changes in testosterone.

J.M.S. was in receipt of an N.E.R.C. post-graduate studentship.

\section{References}

Bubenik, G.A., Bubenik, A.B., Brown, G.M. \& Wilson, D. (1975) The role of sex hormones in the growth of antler bone tissue. Part 1. Endocrine and metabolic effects of antiandrogen therapy. $J$. exp. 20ol. 194, 348-358.

Chapman, D.I. (1975) Antlers-bones of contention. Mamm. Rev. 5, 121-172.

Chesworth, J.M. (1977) Radioimmunoassays of ovine LH and ovine prolactin using polymerised second antisera. Analyt. Biochem. 80, 31-40.

Corker, C.S. \& Davidson, D.W. (1978) A radioimmunoassay for testosterone in various biological fiuids without the use of chromatography. J. Steroid Biochem. 9, 373-374.

Darling, F.F. (1937) A Herd of Red Deer. Oxford University Press, London.

Goss, R.J. (1968) Inhibition of growth and shedding of antlers by sex hormones. Nature, Lond. 204, 798-799.

Katongole, C.B., Naftolin, F. \& Short, R.V. (1971) Relationship between blood levels of luteinising hormone and testosterone in bulls, and the effects of sexual stimulation. J. Endocr. 50, 457-466.

Lee, V.W.K., Cumming, I.A., de Kretser, D.M., Findlay, J.K., Hudson, B. \& Keogh, E.J. (1976) Regulation of gonadotrophin secretion in rams from birth to sexual maturity. 1. Plasma LH, FSH and testosterone levels. J. Reprod. Fert. 46, 1-6.

Lincoln, G.A. (1971 a) Puberty in a seasonally breeding male, the red deer stag (Cervus elaphus L.). J. Reprod. Fert. 25, 41-54.
Lincoln, G.A. (1971b) The seasonal reproductive changes in the adult red deer stag (Cervus elaphus L.). J. Zool., Lond. 163, 105-123.

Lincoln, G.A. (1976) Seasonal variation in the episodic secretion of luteinising hormone and testosterone in the ram. J. Endocr. 69, 213-226.

Lincoln, G.A. \& Davidson, W. (1977) The relationship between sexual and aggressive behaviour, and the pituitary and testicular activity during the seasonal cycle of rams, and the influence of the photoperiod. $J$. Reprod. Fert. 49, 267-276.

Lincoln, G.A. \& Kay, R.N.B. (1979) Effect of season on the secretion of $\mathrm{LH}$ and testosterone in intact and castrated red deer stags (Cervus elaphus). J. Reprod. Fert. 55, 75-80.

Lincoln, G.A., Youngson, R.W. \& Short, R.V. (1970) The social and sexual behaviour of the red deer stag. $J$. Reprod. Fert., Suppl. 11, 71-103.

Lincoln, G.A., Guinness, F.E. \& Short, R.V. (1972) The way in which testosterone controls the social and sexual behaviour of the red deer stag (Cervus elaphus). Horm. \& Behav. 3, 375-396.

Mirarchi, R.E., Howland, B.E., Scanlon, P.F., Kirkpatrick, R.L. \& Sanford, L.M. (1978) Seasonal variation in plasma $\mathbf{L H}, \mathrm{FSH}$, prolactin and testosterone concentrations in adult male white tailed deer. Can. J. Zool. 56, 121-127.

Mitchell, B., McCowan, D. \& Nicholson, I.A. (1976) Annual cycles of body weight and condition in Scottish red deer. J. Zool., Lond. 180, 107-127. 
Mitchell, B., Staines, B.W. \& Welch, D. (1977) Ecology of Red Deer. Institute of Terrestrial Ecology, Cambridge.

Muir, P.D., Barrell, G.K. \& Sykes, A.R. (1982) Modification of antler growth in red deer stags by use of a synthetic progestagen. Proc. N.Z. Soc. Anim. Prod. 42, 145-147.

Pelletier, J. \& Ortavant, R. (1975) Photoperiodic control of $\mathrm{LH}$ release in the ram. 1. Influence of increasing and decreasing light photoperiods. Acta endocr., Copenh. 78, 435-441.

Plotka, E.D., Seal, U.S., Letellier, M.A., Verme, L.J. \& Ozoga, J.J. (1978) Endocrine and morphologic effects of pinealectomy in white tailed deer. In Animal Models for Research on Contraception and Fertility, pp. 452-466. Ed. N. J. Alexander. Harper and Rowe, Hagerstown.

Scaramuzzi, R.J., Caldwell, B.V. \& Moor, R.M. (1970) Radioimmunoassay of $\mathrm{LH}$ and estrogen during the estrous cycle in the ewe. Biol. Reprod. 3, 110-119.
Schulte, B.A., Seal, U.S., Plotka, E.D., Letellier, M.A., Verme, L.J., Ozoga, J.J. \& Parsons, J.A. (1981) The effect of pinealectomy on seasonal changes in prolactin secretion in the white tailed deer (Odocoileus virginianus borealis). Endocrinology 108, 173-178.

Suttie, J.M., Goodall, E.D., Pennie, K. \& Kay, R.N.B. (1983) Winter feed restriction and summer compensation in red deer stags (Cervus elaphus). Br. J. Nutr. 50, (in press).

Tachezy, R. (1956) Uber den Einfluss der Sexialhormone auf das Geweihwachstum der Cerviden. Saugetierk. Mitt. 4, 103-112.

West, N.O. \& Nordan, H.C. (1976) Hormonal regulation of reproduction and the antler cycle in the male Columbian black tailed deer (Odocoileus hemionus columbianus). Part II. The effects of methallibure and hormonal treatment. Can.J. Zool. 54, 1637-1656.

Wislocki, G.B., Aub, J.C. \& Waldo, C.M. (1947) The effects of gonadectomy and administration of testosterone propionate on the growth of antlers in male and female deer. Endocrinology 40, 202-224.

Received 17 May 1983 